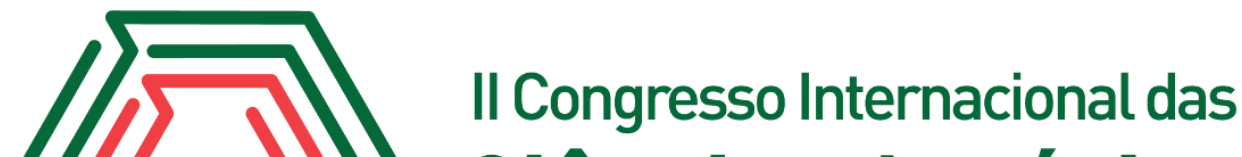 Ciências Agrárias COINTER - PDVAgro 2017
}

\section{ADITIVOS COMBINADOS PARA CONTROLE MICROBIOLÓGICO DE CARNE OVINA}

\author{
Apresentação: Pôster
}

Tasyely Daylhany Freire de Lima ${ }^{1}$ Lucas de Oliveira Soares Rebouças ${ }^{2}$; Claudionor Antonio dos Santos Filho ${ }^{3}$; Maria Carla da Silva Campêlo ${ }^{4}$; Patrícia de Oliveira Lima ${ }^{5}$

\section{Introdução}

A carne é o principal alimento de origem animal presente na dieta humana, sendo cada vez mais requisitada, tanto em quantidade quanto em qualidade. Sua popularidade e preferência se dá por ser um alimento rico em diversos nutrientes, de fácil acesso e de uma enorme diversidade. A carne ovina aos poucos ganha seu mercado consumidor, mas ainda sofre com a rejeição, por não fazer parte das tradições e hábitos do dia a dia.

A conservação de alimentos por aditivos consiste na adição de produtos químicos aos alimentos. Assim como outros processos já estudados, esse método também não é um processo moderno de conservação. Com o avanço da insdústria química, a indústria de alimentos tem sido beneficiada pelo surgimento de novas substâncias que podem ser adicionadas aos alimentos com o objetivo de conservar, melhorar a cor, o aroma, a textura, o sabor, bem como seu valor nutritivo (VASCONCELOS e FILHO, 2010).

Assim, objetivou-se avaliar o efeito do lactato de sódio, tripolifosfato de sódio e a da associação destes na qualidade microbiológica da carne ovina.

\footnotetext{
${ }^{1}$ Graduanda em Zootecnia na Universidade Federal Rual do Semiárido, UFERSA, tasy freire@hotmail.com

2 Pós-graduando na Universidade Federal Rural do Semiárido

${ }^{3}$ Graduando em Zootecnia na Universidade Federal Rural do Semiárido, UFERSA,

${ }^{4}$ Pós-graduando na Universidade Federal Rural do Semiárido

${ }^{5}$ Docente na Universidade Federal Rural do Semiárido, UFERSA, pattlima@ufersa.edu.br
} 


\section{Fundamentação Teórica}

Quando se compara o consumo de carne ovina com as demais, observa-se, segundo o ANUALPEC (2011), o consumo anual per capita de carne ovina no país é em torno de 0,7 Kg, contra um consumo de $39 \mathrm{Kg}$ de carne bovina, 44,5 $\mathrm{Kg}$ de carne de frango e $13 \mathrm{Kg}$ de carne suína. Esta disparidade é resultado do empenho observado nas últimas décadas nestas cadeias mais eficientes, por meio da estruturação, tecnificação e ampliação de suas receitas, consequentemente, a cadeia da ovinocultura deve adotar estas lições para entrar nesta competição e aumentar a quantidade e qualidade da oferta de carne de animais jovens (ALVES et al., 2014). Agora, o desafio da ovino/ caprinocultura mundial se baseia em aumentar o consumo do produto, principalmente nos grandes centros, ganhando assim mais mercado e aceitação.

Para manter a qualidade dessa carne, há diversas opções de conservação, mas o método que Para manter a qualidade dessa carne, há diversas opções de conservação, mas o método que mais se destaca é a marinação, que resulta em alimentos bem conservados e aceitos pelos consumidores. Leite e Fiorelli (2013) acrescentam que o princípio desta técnica é a aplicação de soluções e condimentos através de injeção, massagem ou imersão para conferir à carne melhorias nas suas características organolépticas e aumento no seu prazo de validade, no entanto, o impacto do uso de aditivos sintéticos nessas soluções em diferentes tipos de produtos cárneos ainda demanda mais pesquisas.

\section{Metodologia}

O experimento foi realizado na Universidade Federal Rural do Semi-Árido - UFERSA, as análises microbiológicas foram realizadas no Laboratório de Inspeção de Produtos de Origem Animal (LIPOA). A carne ovina utilizada foi oriunda de 24 animais sem padrão racial definido (SPRD) criados em sistema intensivo em propriedade particular no município de Governador DixSept Rosado/RN, no qual foram abatidos aos 6 meses, o abate dos mesmos foi conduzido no Abatedouro Frigorífico Industrial de Mossoró/RN (AFIM), seguindo protocolo padrão adotado pelo abatedouro.

A amostras foram subdivididas em 4 lotes sendo cada um submetido a um tratamento, onde três destes adicionou-se lactato de sódio (LS) e tripolifosfato de sódio (TPF), além do controle. As amostras foram imersas por 15 minutos em soluções com as concentrações: Lactato de sódio a $5 \%$ + Tripolifosfato a 2,5\% (LS+TP), ácido láctico a 2,5\% + Tripolifosfato a 2,5\% (AL+TP) e Lactato de sódio a $5 \%$ + ácido láctico a 2,5\% + Tripolifosfato a 2,5\% (LS+AL+TP). 
Todas as amostras foram analisadas em triplicatas e período de armazenamento: zero (dia zero), 3, 6, 9 e 12 dias, sob temperatura de $4^{\circ} \mathrm{C} \pm 1^{\circ}$. Posteriormente submetidas a análises para verificação da qualidade microbiológica da carne.

Para as análises microbiológicas, foram pesadas, de maneira asséptica, $25 \mathrm{~g}$ de carne ovina e transferidas para sacos plásticos estéreis, onde foram acrescidos $225 \mathrm{~mL}$ de água peptonada tamponada estéril para posterior homogeneização em "Stomacher" durante 2 minutos, obtendo-se assim a diluição $10^{-1}$, a partir da qual foram obtidas as demais diluições decimais até $10^{-4}$. Após a diluição, as amostras foram submetidas às técnicas de contagem total de bactérias psicrotróficas e bactérias aeróbias mesófilas.

Os dados foram submetidos à análise de variância e teste de comparação de médias. Os efeitos dos diferentes tratamentos sobre cada variável foram comparados por meio do teste de Tukey, ao nível de 5\% de probabilidade, utilizando o SISVAR versão 5.6.

\section{Resultados e Discussões}

No dia 0, os mesófilos na amostra em ácido lático a 2,5\% + Tripolifosfato a 2,5\% (AL+TP), obteve-se a seguinte contagem: 5,55 $\log ^{10} \mathrm{UFC} / \mathrm{g}$; Na amostra em Lactato de sódio a 5\% + ácido láctico a 2,5\% + Tripolifosfato a 2,5\% (LS+AL+TP) obteve-se 6,2 $\log { }^{10} \mathrm{UFC} / \mathrm{g}$; Na amostra em Lactato de sódio a $5 \%$ + Tripolifosfato a $2,5 \%$ (LS+TP), observou-se 6,4 $\log ^{10} \mathrm{UFC} / \mathrm{g}$; E na amostra de controle, o resultado foi de $6,4 \quad \log ^{10} \mathrm{UFC} / \mathrm{g}$. Os resultados obtidos não diferiram estatisticamente.

Tabela 1: Contagem de microrganismos mesófilos e psicrotróficos aeróbios durante armazenamento refrigerado em carne ovina marinada. Fonte: Própria

\begin{tabular}{ccccccc}
\hline \multirow{2}{*}{$\begin{array}{c}\text { Dias de } \\
\text { armazenamento }\end{array}$} & \multirow{2}{*}{ Análises } & \multicolumn{4}{c}{ Aditivos } & \multirow{2}{*}{ CV (\%) } \\
\cline { 3 - 5 } & & Controle & LS+TP & AL+TP & LS+AL+TP & \\
0 & Mesófilos & $6,4 \mathrm{Ca}$ & $6,4 \mathrm{Ca}$ & $5,55 \mathrm{Aa}$ & $6,2 \mathrm{Ab}$ & \multirow{2}{*}{0,85} \\
3 & $\left(\log _{10} \mathrm{UFC} / \mathrm{g}\right)$ & $7,4 \mathrm{Bb}$ & $7,4 \mathrm{Bb}$ & $7,4 \mathrm{Bb}$ & $6,0 \mathrm{Ab}$ & \\
& & & & & \\
0 & Psicotróficos & $6,40 \mathrm{Da}$ & $5,90 \mathrm{Ca}$ & $4,05 \mathrm{Aa}$ & $4,50 \mathrm{Ba}$ & \multirow{2}{*}{0,90} \\
\hline
\end{tabular}

A ,B Letras maiúsculas distintas na linha indicam diferença entre os tratamentos pelo teste Tukey $5 \%$.

a, b, c Letras minúsculas distintas na coluna indicam diferença entre os tempos de armazenamento pelo teste Tukey $5 \%$

No dia 3, para mesófilos, o tratamento LS+AL+TP que apresentou a contagem de 6,0 $\log { }^{10} \mathrm{UFC} / \mathrm{g}$ se destacou em relação aos demais, que obtiveram valores iguais, a saber, 7,4 $\log ^{10} \mathrm{UFC} / \mathrm{g}$. 
De acordo com a literatura, níveis de contaminação por mesófilos de 2 a $5 \log U F C / g$ em carnes podem indicar condições higiênicas adequadas no abate e contagens acima de $6 \operatorname{logUFC/g}$ podem significar condições inadequadas (GILL, 1998) e indicar início do processo de deterioração com produção de odor desagradável e comprometimento da vida de prateleira. Lopes et al., (2007) avaliaram a contaminação por microrganismos mesófilos em carcaças de frango, encontrando valores médios de 6,4, semelhante a presente pesquisa.

Comparando-se os resultados do dia 0 e do dia 3, observa-se crescimento microbiológico significativo de mesófilos, porém o tratamento LS+AL+TP foi o que apresentou o crescimento menos significativo entre os dias 0 e 3 . Para os psicotróficos, no dia 0 , os resultados obtidos foram os seguintes: 4,05 $\log ^{10} \mathrm{UFC} / \mathrm{g}$ para AL+TP; 4,5 $\log { }^{10} \mathrm{UFC} / \mathrm{g} \mathrm{LS}+\mathrm{AL}+\mathrm{TP} ; 5,9 \log ^{10} \mathrm{UFC} / \mathrm{g} \mathrm{LS}+\mathrm{TP}$; $6,4 \log { }^{10} \mathrm{UFC} / \mathrm{g}$ no tratamento controle. Para os psicotróficos no dia 3, o tratamento LS+AL+TP se destacou (6,60 $\left.\log ^{10} \mathrm{UFC} / \mathrm{g}\right)$, seguido pelo AL+TP (7,20 $\left.\log { }^{10} \mathrm{UFC} / \mathrm{g}\right)$. O LS+TP não diferiu estatisticamente do controle $\left(7,40 \log { }^{10} \mathrm{UFC} / \mathrm{g}\right)$. Apesar dos tratamentos que possuem ácido láctico terem apresentados melhores resultados, deve-se ter cautela com o seu uso, pois o mesmo pode causar alteração do sabor, tornando o sabor muito ácido, podendo provocar rejeição dos consumidores. Infere-se, portanto, que as combinações dos umectantes utilizados, possuem baixos efeitos sobre as carnes resfriadas, provavelmente devido à elevada contaminação inicial do material.

\section{Conclusões}

A associação dos aditivos lactato de sódio, tripolifosfato de sódio e ácido lático, nas combinações e proporções adotadas neste estudo, não promoveu efeito antimicrobiano na carne contaminada.

\section{Referências}

ALVES, Luís Gustavo Castro et al. Produção de carne ovina com foco no consumidor. Enciclopédia Biosfera, Goiânia, v. 10, n. 18, p.2399-2014, jul. 2014. Disponível em: <http://www.conhecer.org.br/enciclop/2014a/AGRARIAS/producao de carne.pdf>. Acesso em: 10 Setem. 2017.

ANUALPEC. Anuário da pecuária brasileira. 19.ed. São Paulo: Instituto FNP, 2011. 360p.

GILL, C. O. Microbiological contamination of meat during slaughter and butchering of cattle, sheep and pigs. 1998. In: DAVIES, A.; BOARD, R. The Microbiology of Meat and Poultry. London: Blackie Academic and Professional.. 
LEITE, Cláudio Eduardo Cartabiano; FIORELLI, Rogério Balotin. DESENVOLVIMENTO DE UM MARINADO A BASE DE CARNE DE POEDEIRAS DE DESCARTE. 2013. 54 f. TCC (Graduação) - Curso de Tecnologia de Alimentos, Universidade Tecnológica Federal do Paraná, Francisco Beltrão, 2013. Disponível em: <http://repositorio.roca.utfpr.edu.br/jspui/bitstream/1/2088/1/FB_COALM_2013_1_05.pdf>. Acesso em: 15 Setem. 2017.

LOPES, M. et al. Pesquisa de Salmonella spp. e microorganismos indicadores de carcaças de frango e água de tanques de pré-resfriamento em abatedouros de aves. 2007. Semina: Ciências Agrárias, Londrina, v. 28, n. 3, p. 465-476, jul./set. 2007,

VASCONCELOS, M. A. S.; MELO FILHO, A. B. Conservação dos alimentos. 2010. Técnico em Alimentos, Universidade Federal Rural de Pernambuco, Brasil. Disponível em: <http://proedu.ifce.edu.br/bitstream/handle/123456789/316/Cons_Alimentos.pdf?sequence=2>. 